\title{
Article
}

\section{Impacts of COVID-19 on Animals in Zoos: A Longitudinal Multi-Species Analysis}

\author{
Ellen Williams ${ }^{1,2, *,+}+\mathbb{D}$, Anne Carter ${ }^{1,+}+\mathbb{D}$, Jessica Rendle ${ }^{3,4,+} \mathbb{D}$ and Samantha J. Ward ${ }^{1,+}+\mathbb{D}$ \\ 1 School of Animal, Rural \& Environmental Sciences, Nottingham Trent University, Brackenhurst Campus, \\ Nottinghamshire NG25 0QF, UK; anne.carter@ntu.ac.uk (A.C.); samantha.ward@ntu.ac.uk (S.J.W.) \\ 2 Department of Veterinary Health \& Animal Sciences, Harper Adams University, Newport, \\ Shropshire TF10 8NB, UK \\ 3 Twycross Zoo, Atherstone, Warwickshire CV9 3PX, UK; j.rendle@murdoch.edu.au \\ 4 Conservation Medicine, College of Science Health, Education and Engineering, Murdoch University, \\ Perth 6150, Australia \\ * Correspondence: ewilliams@harper-adams.ac.uk \\ + All authors had an equal contribution.
}

check for updates

Citation: Williams, E.; Carter, A.; Rendle, J.; Ward, S.J. Impacts of COVID-19 on Animals in Zoos: A Longitudinal Multi-Species Analysis. J. Zool. Bot. Gard. 2021, 2, 130-145. https://doi.org/10.3390/jzbg2020010

Academic Editor: Katherine A. Cronin

Received: 24 February 2021

Accepted: 12 March 2021

Published: 30 March 2021

Publisher's Note: MDPI stays neutral with regard to jurisdictional claims in published maps and institutional affiliations.

Copyright: (C) 2021 by the authors Licensee MDPI, Basel, Switzerland. This article is an open access article distributed under the terms and conditions of the Creative Commons Attribution (CC BY) license (https:// creativecommons.org/licenses/by/ $4.0 /$ )

\begin{abstract}
Prolonged and repetitive COVID-19 facility closures have led to an abrupt cessation of visitors within UK and Irish zoos for variable periods since March 2020. This study sought to increase understanding of the impact of closures and reopenings on animal behaviour, thereby broadening understanding of whether zoo animals habituate to visitors. Data were collected from June to August 2020 at two UK facilities on eight species ( $n=1$ Chinese goral, $n=2$ Grevy's zebra, $n=11$ swamp wallaby, $n=2$ Rothschild's giraffe, $n=2$ nyala, $n=4$ Chapman's zebra, $n=2$ snow leopard and $n=3$ Amur leopard). Behaviour change and enclosure use was variable across species but most changes were non-significant. Grevy's zebra engaged in more comfort behaviour during closure periods than post-closure $(p<0.05)$. Chinese goral engaged in more environmental interactions during closure periods $(p<0.05)$. Grevy's zebra spent longer than would be expected by chance closest to public viewing areas during closure periods $(p<0.008)$. These results suggest variable impacts of covid-19 closures and reopenings, mirroring human-animal interaction literature. We highlight the potential for some species to take longer to re-habituate to the presence of zoo visitors. As facility closures/reopenings are ongoing, we advocate a longitudinal monitoring approach. Furthermore, we recommend incorporation of physical and physiological measures of welfare where possible, alongside behavioural responses, to enable a holistic approach to answering fundamental questions on whether zoo animals habituate to visitors.
\end{abstract}

Keywords: COVID-19; zoo; behaviour; multi-species; visitor-animal interactions

\section{Introduction}

Zoo animals around the world experience the visiting public on a daily basis. With the majority of animals that currently live in zoos having been born in captivity, these visitations have occurred throughout their lives. Systematic investigations into the impacts of visitors on zoo animal behaviour and welfare (termed 'the visitor effect') began in the late 1980s [1] and have accelerated thanks to Hosey's [2] model. Sherwen et al. [3] reviewed the published literature on zoo human-animal interactions (HAIs) and outlined a mixed response between positive, neutral and negative implications. They proposed the likely cause of variations as species-specific differences, individual characteristics, enclosure design and the nature of the interactions. The studies included in the review only had the opportunity to compare low with high visitor numbers, none of the studies compared with a control period of 'no visitors' when the zoos were closed during normal daylight hours. Although some facilities do close (e.g., Tayto Park, Ireland) or operate on reduced opening days (e.g., Knowsley Safari Park, England) over winter periods, during which time visitors 
are not present, there is currently no published literature which assesses animal behaviour during this time. Whether visitors have a positive or negative effect on zoo animals may be variable, but on the whole, they are a constant stimulus in a zoo animals' environment.

The COVID-19 pandemic led to an abrupt cessation of visitors in zoological facilities throughout the world. Within the UK specifically, England, Scotland, Wales and Northern Ireland followed different rulings under different governmental guidance but all zoological facilities were closed in March and did not begin to reopen until mid-June. Aside from facilities which close periodically throughout the year, this is the first time that zoos have forcibly had to close to the public for a prolonged period of time, yet still remain open for staff to maintain and care for the animals. As closures came during the Spring-Summer period, these would be periods of time that most facilities in the UK and Ireland would all usually be open seven days per week. Although the impacts of the zoo closures are having detrimental effects to the financial viability and survivability of zoos [4], this provided an opportunity to investigate the long-term impact of visitor presence (and absence) on zoo animal behaviour.

Previous research has indicated behavioural change in slender-tailed meerkats (Suricata suricatta) between observations during and post COVID-19 closures but no behavioural changes in African penguins (Spheniscus demersus) [5] and anecdotal reports on social media and in national newspapers indicated animals either 'shying away' from humans (e.g., garden eels (Heteroconger hassi) hiding when keepers approached their enclosures [6]), or 'looking out' for humans (e.g., primates going up to windows [7] and parrots whistling to keepers for attention [8]), during closure periods [9]. However, whether this is applicable to a wider range of species or whether a period of habituation is experienced as visitors return is unknown. Understanding behavioural change in zoo animals as a result of prolonged closure periods enables an advanced understanding of visitor-animal interactions and the potential implications for zoo animals. With facilities continuing to close and then reopen around the world as the pandemic continues, it is paramount that the impact of this on zoo animals is understood for the benefit of the animals but also to allow an increased understanding of the fundamental questions surrounding habituation of animals to humans. Increased knowledge in this area will enable targeted animal management which optimises species welfare.

The aim of this research was to systematically analyse data collected opportunistically by zoo staff during this unique closure period and to investigate whether the behavioural changes observed in slender-tailed meerkats [5] were observed in this wider subset of species. Monitoring over a longer period of time enabled an investigation into habituation to zoo visitors in the study species, once facilities reopened. We hypothesised that the long-periods of time without exposure to zoo visitors would have led to animals adopting one of two behavioural responses when facilities reopened: (i) avoidance of visitorsspending time in areas furthest away from the public and showing increased vigilance towards zoo visitors; or (ii) attraction towards visitors-spending time trying to interact with members of the public and spending time in areas of their enclosure which were closest to where the public were. We also anticipated that there would be variation in behavioural responses observed across species, due to the range of species analysed as part of this multi-species approach.

\section{Materials and Methods}

\subsection{Subjects and Study Sites}

Subjects were Chinese goral (Naemorhedus griseus: $n=1$ ), Grevy's zebra (Equus grevyi: $n=2$ ), swamp wallaby (Wallabia bicolor: $n=11$ ), Rothschild's giraffe (Giraffa camelopardalis rothschildi: $n=2)$, nyala (Tragelaphus angasii: $n=2)$, Chapman's zebra (Equus quagga chapmani: $n=4$ ), snow leopard (Panthera uncia: $n=2$ ) and Amur leopard (Panthera pardus orientalis: $n=3)$. Swamp wallaby at Zoo A were housed in a walk-through exhibit. Rothschild's giraffe and nyala at Zoo B were housed together in a mixed-species exhibit. All other 
species were housed in standard enclosures that were non-mixed species exhibits. Details of species and observation periods are included in Table 1.

Table 1. Details of study sites and periods of data collection. $\mathrm{M}=$ male, $\mathrm{F}=$ female.

\begin{tabular}{|c|c|c|c|c|c|c|}
\hline \multirow{2}{*}{ Study Site } & \multirow{2}{*}{$\begin{array}{l}\text { Species (Number of } \\
\text { Individuals) }\end{array}$} & \multirow{2}{*}{$\begin{array}{l}\text { Period of Data } \\
\text { Collection }\end{array}$} & \multirow{2}{*}{ Date of Reopening } & \multirow{2}{*}{$\begin{array}{l}\text { Frequency of } \\
\text { Observations }\end{array}$} & \multicolumn{2}{|c|}{ Number of Observation Days } \\
\hline & & & & & Closed & Open \\
\hline \multirow{3}{*}{ Zoo A } & $\begin{array}{c}\text { Chinese goral } \\
(n=1,1 \mathrm{M})\end{array}$ & June-August 2020 & \multirow{3}{*}{ End of June 2020} & $1-2$ per day & 5 & 31 \\
\hline & $\begin{array}{l}\text { Grevy's Zebra } \\
\quad(n=2,2 \mathrm{~F})\end{array}$ & June-August 2020 & & $1-2$ per day & 4 & 26 \\
\hline & $\begin{array}{l}\text { Swamp wallaby } \\
(n=11,3 \mathrm{M} 8 \mathrm{~F})\end{array}$ & June-August 2020 & & $2-6$ per day & 3 & 29 \\
\hline \multirow{5}{*}{ Zoo B } & $\begin{array}{l}\text { Rothschild's giraffe } \\
\quad(n=2,2 \mathrm{M})\end{array}$ & June-July 2020 & \multirow{5}{*}{ Mid June 2020} & $1-2$ per day & 3 & 18 \\
\hline & $\begin{array}{c}\text { Nyala } \\
(n=2,2 \mathrm{~F})\end{array}$ & June-July 2020 & & $1-2$ per day & 3 & 15 \\
\hline & $\begin{array}{l}\text { Chapman's Zebra } \\
(n=4,4 \mathrm{M})\end{array}$ & June 2020 & & $1-2$ per day & 5 & 3 \\
\hline & $\begin{array}{l}\text { Snow leopard } \\
(n=2,1 \mathrm{M} 1 \mathrm{~F})\end{array}$ & June-July 2020 & & $1-2$ per day & 3 & 3 \\
\hline & $\begin{array}{l}\text { Amur leopard } \\
(n=3,3 \mathrm{~F})\end{array}$ & June-August 2020 & & $1-2$ per day & 3 & 11 \\
\hline
\end{tabular}

\subsection{Data Collection}

\subsubsection{Behavioural Observations}

Zoo staff collected data whilst their facility was still closed to the public (June 2020) and once facilities reopened to the public (June to August 2020). Once the sites were open, all facilities had restricted visitor numbers compared to pre-COVID times following guidance from The Global Association of Attractions Industry [10] (2020: an allocation of at least 28.3-square-foot circle per person), and varied according to their respective local government restrictions. Behavioural observations were undertaken 1-6 times per day, according to staff availability (Table 1). Each observation period lasted five minutes. The number of observations per site in open and closed conditions were: Chinese goral-7 closed, 55 open; Grevy's zebra— 5 closed, 46 open; swamp wallaby -6 closed, 58 open; Rothschild's giraffe6 closed, 20 open; nyala -6 closed, 17 open; Chapman's zebra -7 closed, 3 open, snow leopards- 5 closed, 3 open and Amur leopards- 5 closed, 12 open.

Time of behavioural observations varied between facilities, but observations were split relatively evenly throughout the working day and were kept consistent within facilities. Observations were not taken during periods when keepers were interacting directly with the animals (e.g., for training or feeding). All observers were experienced with the study subjects and had extensive experience of behavioural observations as part of routine animal management protocols.

At each 5-min sampling period, behaviours being performed by the animals were recorded using instantaneous scan sampling with a one-minute inter-scan interval. For Chapman's zebra, Rothschild's giraffe, nyala and swamp wallaby the whole group was treated as one sample point. All behaviours being performed by individuals within the group were recorded which enabled identification of presence or absence of behaviours within the study group, at each behavioural scan. However, for the Grevy's zebra, snow leopards and Amur leopards, the frequency of behaviour per individual animal was recorded ( $n=2, n=2$, and $n=3$ respectively). Individual identification was not noted so unique analysis could not be undertaken. For all species, a total sum of frequencies per behaviour at each five-minute scan was used to create a single observation period for statistical analysis. For Chapman's zebra, Rothschild's giraffe, nyala, swamp wallaby and Chinese goral this resulted in a maximum of 6 scans per behaviour per observation period. 
For Grevy's zebra and snow leopard there was a maximum of 12 scans per behaviour per observation period. For Amur leopards, there was a maximum of 18 scans per behaviour per observation period. Behaviours were recorded according to a pre-defined ethogram (Table 2).

Table 2. Ethogram of behaviours for study animals during the study period [5].

\begin{tabular}{ll}
\hline Behaviour & Description \\
\hline Vigilant & $\begin{array}{l}\text { Alert-showing a heightened awareness of their environment (including looking } \\
\text { at visitors) }\end{array}$ \\
\hline Human-animal interaction (positive) & Moving towards or seeking interaction from humans \\
\hline Human-animal interaction (negative) & Avoiding, moving away from or showing fear of humans \\
\hline Foraging/feeding & Locating and consuming foodstuffs \\
\hline Comfort & Any self-maintenance or self-grooming behaviour \\
\hline Social (positive) & Engaging in positive social behaviours (e.g., social play, grooming) \\
\hline Social (negative) & Engaging in negative social behaviour (e.g., fighting, displaying) \\
\hline Locomotion & Moving around the enclosure (on land or in water) in a non-repetitive pattern \\
\hline Interaction with the environment & $\begin{array}{l}\text { Investigating or interacting with things in the environment (other than food). For } \\
\text { meerkats this also included digging behaviour. }\end{array}$ \\
\hline Resting/sleeping & Sitting or lying motionless with eyes closed. No other behaviour is being performed. \\
\hline Abnormal repetitive behaviour (ARBs) & Repetitive behaviour with no obvious function or purpose \\
\hline Other & Any other behaviour not detailed in the ethogram \\
\hline Out of sight & Animal out of sight of observer \\
\hline
\end{tabular}

\subsubsection{Enclosure Usage}

Enclosures were split into three approximately equal zones (closest third to visitors, middle third, third furthest away from visitors). The locations with animals in were recorded at the start of each observation period. All areas of the enclosure in which individuals were in were recorded.

\subsection{Data Analysis}

Data were split into two periods for analysis: (i) during COVID-19 closures, no visitors and skeletal staff (hereafter 'closed'), (ii) post-reopening, visitors present but under local government social distancing restrictions i.e., reduced numbers compared to 'normal' (hereafter 'open'). Further analyses, undertaken to establish whether behavioural changes were 'short' or 'long' term were undertaken. Data were split into three periods (i) during COVID-19 closures ('closed'), (ii) the first month post re-opening ('Open $<1$ month'), (iii) more than one month post re-opening ('Open $>1$ month'). To account for variation in data collection periods, differences in site/local government restrictions, and potential numbers of visitors entering different facilities, all statistical analysis was done 'within zoo'. Results are compared across facilities to aid in interpretation of findings. Significance values were set at 0.05 , unless corrected for pairwise comparisons. All analyses were undertaken using SPSS Version 26 (SPSS Inc., Chicago, IL, USA). Changes in frequency of behaviour when closed versus when open were assessed using a Mann-Whitney U Test. Bonferroni adjustments were applied to post hoc analyses (reducing the significance value to $p=0.008$ ). Changes in frequency of behaviour when closed as compared to open $<1$ month and open $>1$ month were assessed using a Kruskal Wallis Test with Dunn's post-hoc tests where appropriate. An overview of inferential statistics undertaken is provided in Table 3. Change over time assessments were done for all species except Chapman's zebra and snow leopard; observations were not undertaken open > 1 month for Chapman's zebra and only one observation was undertaken during that period for snow leopard. 
Table 3. An overview of behaviours recorded per species and inferential statistics performed.

\begin{tabular}{|c|c|c|}
\hline Species & $\begin{array}{l}\text { Behaviours on Which Inferential } \\
\text { Statistics Were Performed }\end{array}$ & $\begin{array}{l}\text { Behaviours Not Analysed Statistically Due to Low } \\
\text { Occurrence/Absence }\end{array}$ \\
\hline Amur leopard & $\begin{array}{l}\text { Vigilant } \\
\text { Feeding } \\
\text { Locomotion } \\
\text { Resting } \\
\text { HAI Negative } \\
\text { ARBs } \\
\text { OOS }\end{array}$ & $\begin{array}{l}\text { Environmental interactions ( } n=1 \text { observation) } \\
\text { Comfort, social positive, social negative, HAI positive } \\
\text { ( } n=0 \text { observations) }\end{array}$ \\
\hline Snow leopard & $\begin{array}{l}\text { Resting } \\
\text { OOS }\end{array}$ & $\begin{array}{l}\text { Vigilant, feeding, locomotion, HAI positive, HAI } \\
\text { negative, ARBs, comfort, social positive, social negative, } \\
\text { environmental interactions ( } n=0 \text { observations) }\end{array}$ \\
\hline Chinese goral & $\begin{array}{c}\text { Vigilant } \\
\text { Feeding } \\
\text { Locomotion } \\
\text { Environmental interactions } \\
\text { Resting } \\
\text { OOS }\end{array}$ & $\begin{array}{l}\text { Lone housed so social interactions (positive/negative) } \\
\text { not applicable. } \\
\text { Comfort, ARBs, HAI positive and HAI negative } \\
\text { ( } n=0 \text { observations })\end{array}$ \\
\hline Rothschild giraffe & $\begin{array}{c}\text { Vigilant } \\
\text { Feeding } \\
\text { Social positive } \\
\text { Social negative } \\
\text { Locomotion } \\
\text { Environmental interactions } \\
\text { Resting }\end{array}$ & $\begin{array}{l}\text { Positive HAI ( } n=1 \text { observation) } \\
\text { HAI negative, comfort, ARBs, OOS ( } n=0 \text { observations) }\end{array}$ \\
\hline Chapman's zebra & $\begin{array}{c}\text { Vigilant } \\
\text { Feeding } \\
\text { Social positive } \\
\text { social negative } \\
\text { Locomotion } \\
\text { Environmental interactions } \\
\text { Resting } \\
\text { HAI Positive } \\
\text { Comfort }\end{array}$ & $\begin{array}{l}\text { HAI negative, ARBs, OOS } \\
\qquad(n=0 \text { observations })\end{array}$ \\
\hline Grevy's zebra & $\begin{array}{l}\text { Vigilant } \\
\text { Feeding } \\
\text { Comfort } \\
\text { Social positive } \\
\text { Locomotion } \\
\text { Resting } \\
\text { OOS }\end{array}$ & $\begin{array}{l}\text { HAI positive, HAI negative, negative social interactions, } \\
\text { ARBs and environmental interactions } \\
\qquad(n=0 \text { observations })\end{array}$ \\
\hline Nyala & $\begin{array}{l}\text { Vigilant } \\
\text { Feeding } \\
\text { Locomotion } \\
\text { Resting } \\
\text { OOS }\end{array}$ & $\begin{array}{l}\text { HAI positive, HAI negative, comfort, social positive, } \\
\text { social negative, Environmental interactions, ARBs } \\
\text { ( } n=0 \text { observations })\end{array}$ \\
\hline Swamp wallaby & $\begin{array}{c}\text { Vigilant } \\
\text { Feeding } \\
\text { Comfort } \\
\text { Social positive } \\
\text { Locomotion } \\
\text { Resting } \\
\text { Environmental interaction }\end{array}$ & $\begin{array}{l}\text { HAI positive, HAI negative, social negative, ARBs, OOS } \\
\qquad(n=0 \text { observations })\end{array}$ \\
\hline
\end{tabular}


Statistical analyses related to enclosure usage are as per those described in Williams et al. [5]. For completeness, they have been repeated here. The spread of participation index $[11,12]$ was used to evaluate enclosure zone usage using the formula: $\mathrm{SPI}=\left(\mathrm{S} \mid \mathrm{f}_{\mathrm{O}}-\right.$ $\left.\mathrm{f}_{\mathrm{e}} \mathrm{l}\right) /{ }^{*}\left(\mathrm{~N}-\mathrm{f}_{\mathrm{e} \text { min }}\right)$ whereby $\mathrm{f}_{\mathrm{o}}$ is the observed frequency of scans in each zone, $\mathrm{f}_{\mathrm{e}}$ is the expected frequency for each zone and $\mathrm{f}_{\mathrm{e} \text { min }}$ the expected frequency in the smallest zone. A value of 0 suggests equal use of all zones, whereas a value of 1 suggests exclusive use of one zone. To determine how enclosure use differed (in terms of use of enclosure zones) during the observation periods, a chi-square test of independence with Bonferroni-corrected post hoc tests was applied. A corrected significance of 0.008 applied for a comparison between closed and open (combined). Corrected significance of 0.006 applied for a comparison between closed, open $<1$ month and open $>1$ month.

\subsection{Ethics Statement}

All research protocols were approved by Nottingham Trent University, School of Animal, Rural and Environmental Sciences School Ethics Group (reference number ARE192042) and meet the ARRIVE guidelines where necessary. Permission to conduct the study was granted by the participating zoos prior to commencement of data collection.

\section{Results}

The number of observation sessions during open and closure periods varied across species: Chinese goral—seven closed, 55 open; Grevy's zebra—five closed, 46 open; swamp wallaby—six closed, 58 open; Rothschild's giraffe—six closed, 20 open; nyala—six closed, 17 open; Chapman's zebra-seven closed, three open; snow leopards-five closed, three open and Amur leopards-five closed, 12 open. An overview of observed behaviour across all species is detailed in Figure 1a-h.

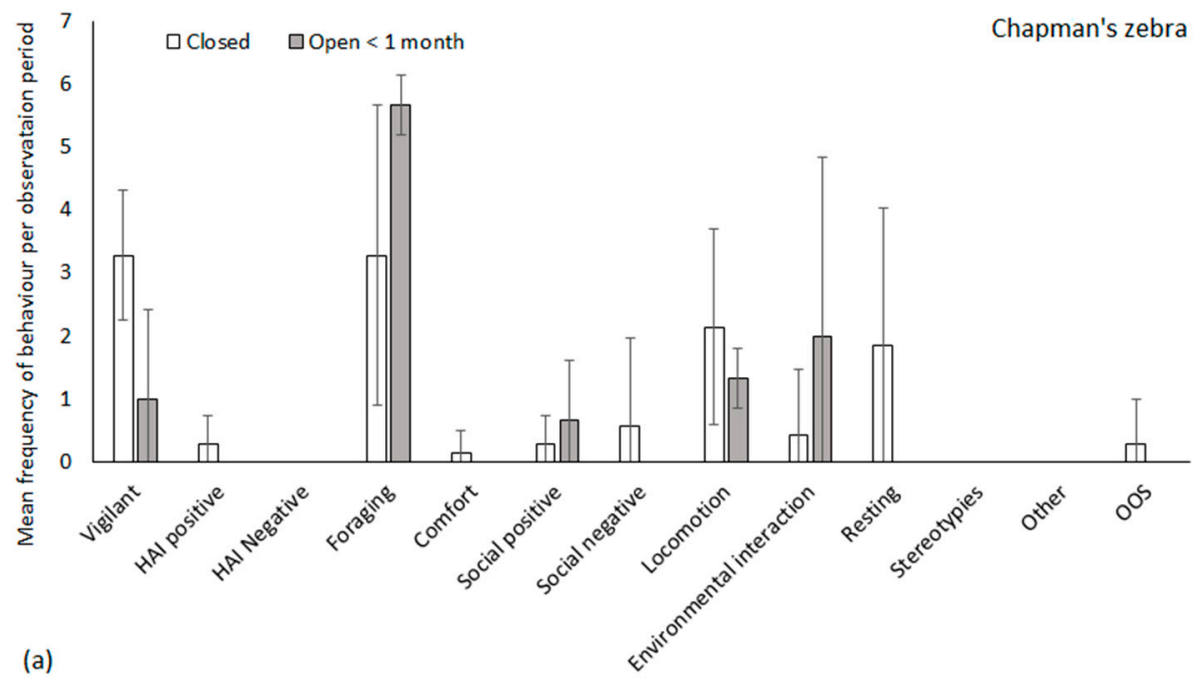

Figure 1. Cont. 


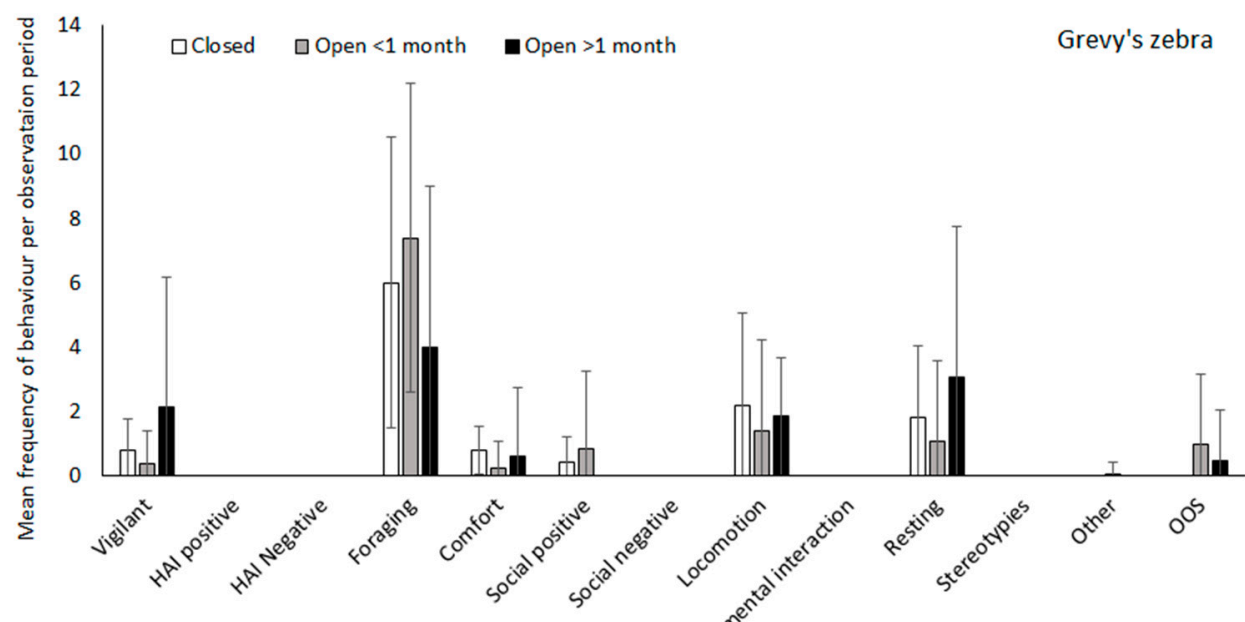

(b)
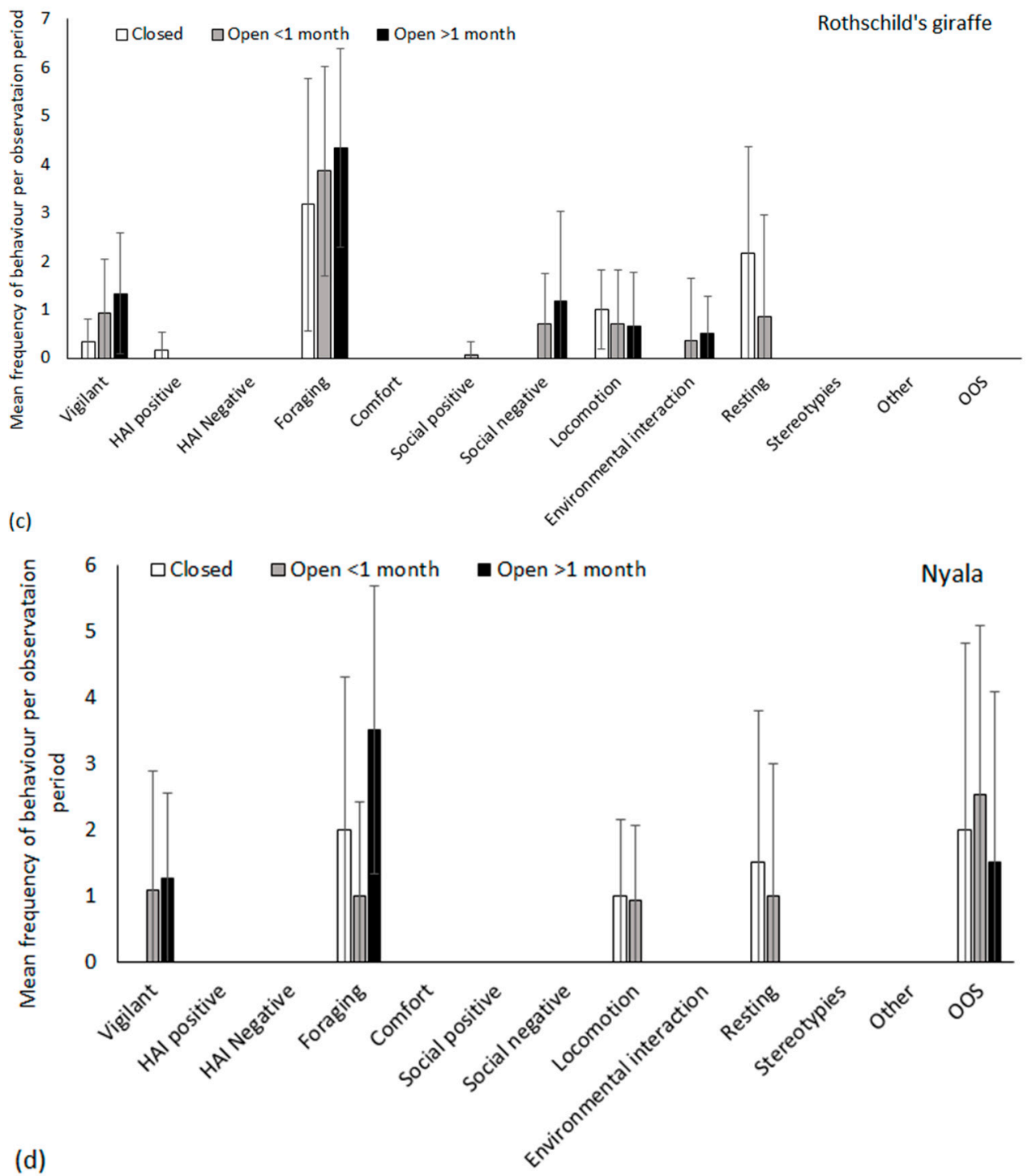

Figure 1. Cont. 

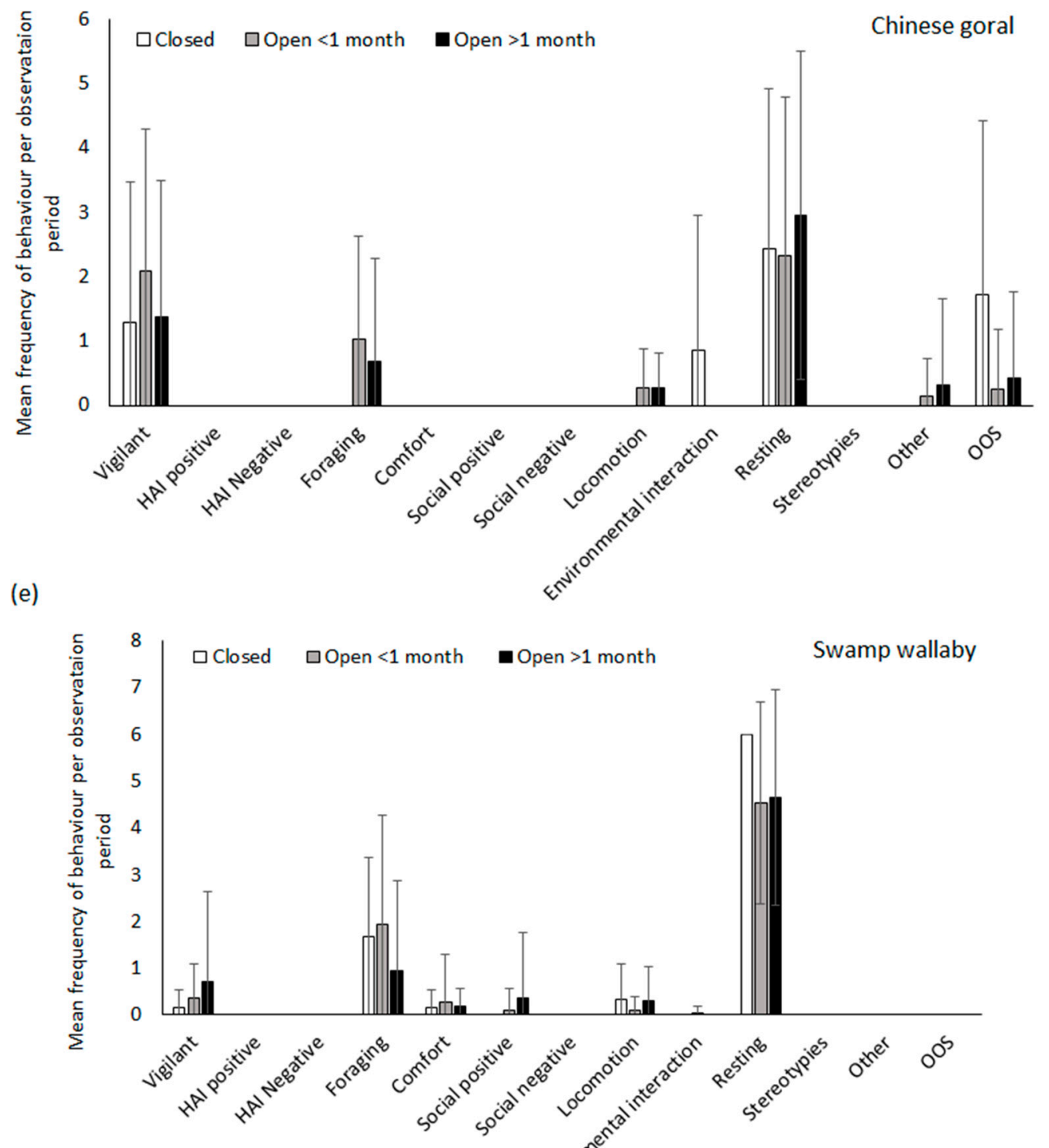

(f)

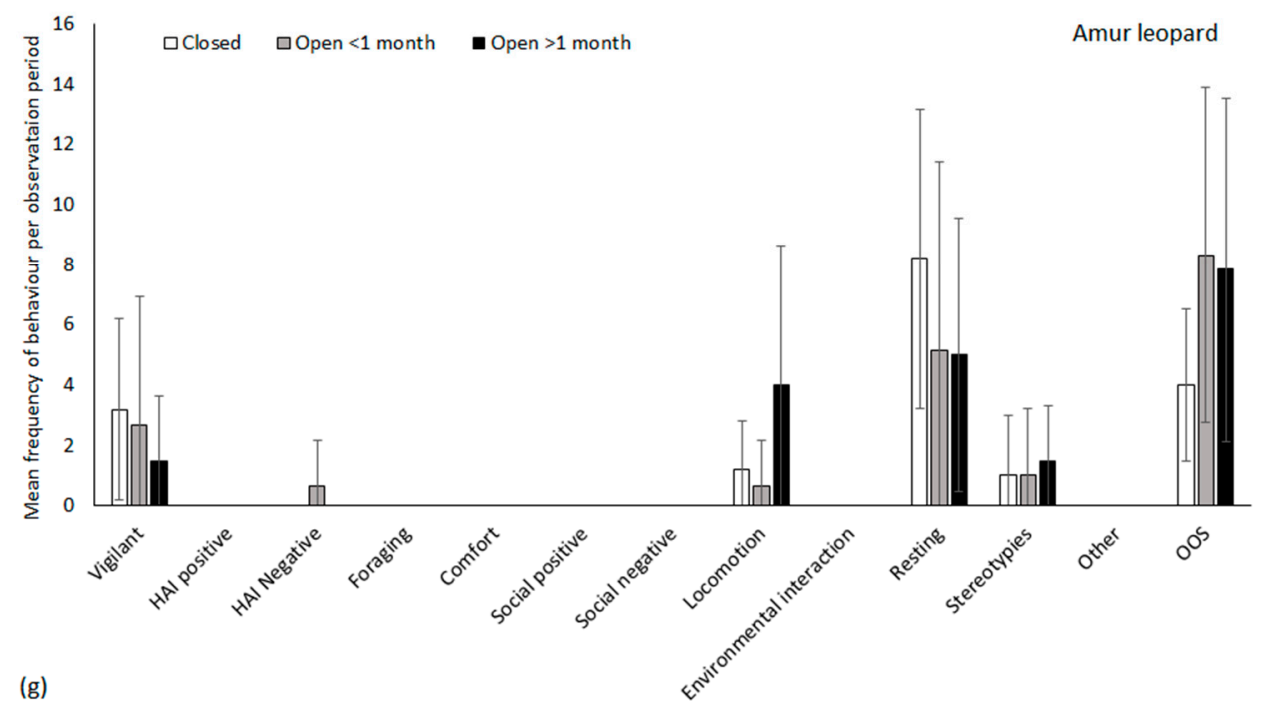

Figure 1. Cont. 


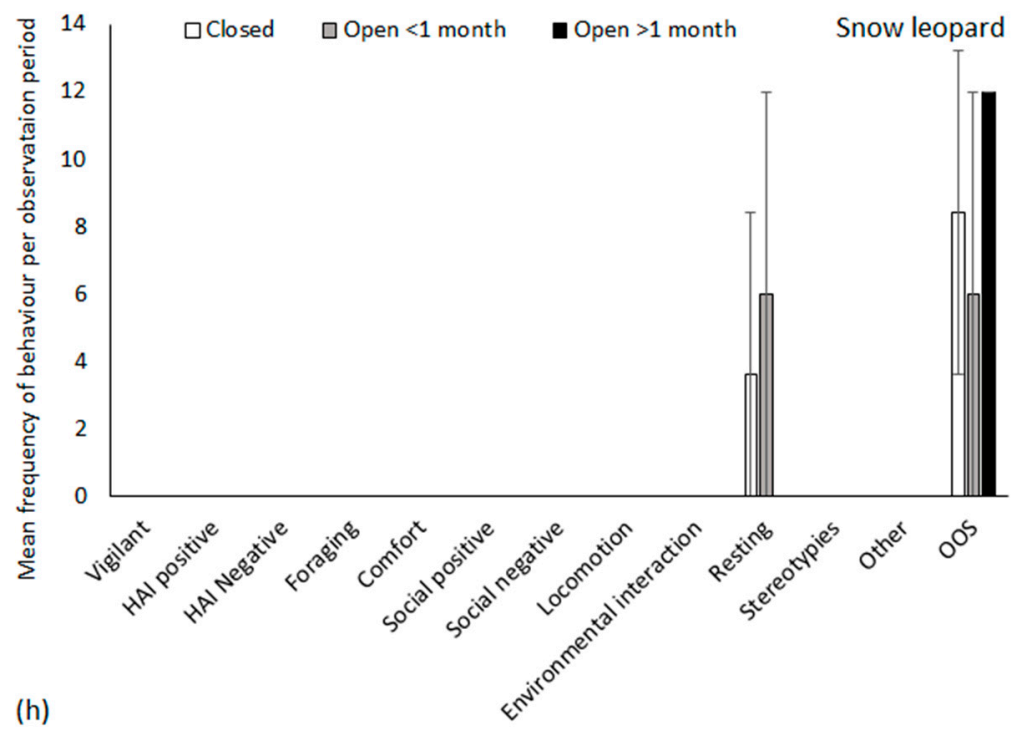

Figure 1. (a-h) An overview of behaviour in the study species during facility closure, the first month post-reopening and more than one-month post reopening. Mean values are based on frequency of behaviour performed by the study group per five-minute observation period. Maximum frequency of observations was six per five-minute period for Chapman's zebra, nyala, Rothschild's giraffe, Chinese goral and swamp wallaby. Maximum frequency of observations was 12 per five-minute period for Grevy's zebra and snow leopard and 18 per five-minute period for Amur leopard. Error bars represent standard deviation.

\subsection{Behavioural Frequency}

Fluctuations in behaviour were observed across all species (Figure 1a-h) however significant differences in frequency of performance was not always detected. There were however incidences of behaviour that we wish to bring attention to for potential biological importance. Nyala showed no vigilance behaviour during closure periods but some vigilance during opening periods, of similar levels open $<1$ month and open $>1$ month. Nyala also initially showed a decrease in feeding behaviour (open $<1$ month) but an increase during the open $>1$ month period (to higher than closure periods). Rothschild's giraffe showed a steady increase in both vigilant and feeding behaviour over time (closed to open $>1$ month), whilst resting behaviour decreased and no resting was observed in the open $>1$ month collection period. Chinese goral showed an increase in vigilance behaviour during the open $<1$ month data collection period, but this reduced to closure levels by open $>1$ month. Chapman's zebra showed a decrease in vigilance behaviour when the facility opened and an increase in feeding, whilst Grevy's zebra showed fluctuation in vigilance and feeding behaviour. Swamp wallabies showed increased vigilance over time (closed to open $>1$ month) but spent the majority of observations resting in all time periods. Amur leopards showed reduced vigilance over time (closed to open $>1$ month) and increased locomotion during the open $>1$ month period. Snow leopards were either resting or out of sight on all observations, regardless of time period.

Grevy's zebra engaged in more comfort behaviour during zoo closure periods (mean \pm SD scans, $0.8 \pm 0.37)$ than when the zoo was open $(0.35 \pm 0.2)(U=61.2, Z=-2.860$, $p=0.04)$. Chinese goral engaged in more environmental interactions during closure periods $(0.86 \pm 0.86)$ than when the facility was open; no environmental interactions were observed when the zoo was open $(U=165, Z=-2.803, p=0.005)$. For all other species there were no significant changes in frequency of behaviours $(p>0.05)$.

When behaviours were investigated over time after reopening, Grevy's zebra engaged in more comfort behaviour during closure periods $(0.8 \pm 0.37)$ than open $<1$ month $(0.24 \pm 0.14)$ or open $>1$ month $(0.62 \pm 0.62)\left(\mathrm{H}_{(2)}=8.184, p=0.017\right)$. There was no significant difference in frequency of comfort behaviour between open $<1$ month and 
open $>1$-month data collection periods $(p>0.05)$. No other significant differences in behaviours were observed for Grevy's zebra, or for the other study species $(p>0.05)$.

\subsection{Enclosure Usage}

SPI values during open and closed periods at the study zoos are provided in Table 4. Although inferential statistics could not be undertaken on these data, descriptive analysis indicates SPI values differed across species and variations were seen in SPI values between open and closure periods.

Table 4. SPI values during open and closed periods for all of the study species. A value of 0 suggests equal use of all zones, whereas a value of 1 suggests exclusive use of one zone.

\begin{tabular}{|c|c|c|c|c|c|}
\hline \multirow{2}{*}{ Facility } & \multirow{2}{*}{ Species } & \multicolumn{4}{|c|}{ Spread of Participation Index } \\
\hline & & Closed & $<1$ Month Open & >1 Month Open & Overall Open \\
\hline \multirow{3}{*}{ A } & Chinese goral & 0.14 & 0.37 & 0.42 & 0.39 \\
\hline & Grevy's zebra & 0.7 & 0.18 & 0.38 & 0.21 \\
\hline & Swamp wallaby & 0.25 & 0.19 & 0.19 & 0.19 \\
\hline \multirow{5}{*}{$\mathrm{B}$} & Chapman's zebra & 0.35 & 0.5 & - & 0.5 \\
\hline & Rothschild's giraffe & 0.5 & 0.18 & 0.25 & 0.1 \\
\hline & Nyala & 0.5 & 0.5 & 0.62 & 0.47 \\
\hline & Amur leopard & 0.18 & 0.31 & 0.25 & 0.25 \\
\hline & Snow leopard & 1 & 0.5 & - & 0.5 \\
\hline
\end{tabular}

Apart from Grevy's zebra, there was no difference from what would be expected by chance between enclosure use for any of the species when the two sites were closed or open, or between closure, open $<1$ month and open $>1$ month $(p>0.05)$. Enclosure use differed for Grevy's zebra during open and closure periods $\left(\chi^{2}=9.040, \mathrm{df}=2, p=0.011\right)$. Post hoc assessments revealed that zebra spent longer than would be expected by chance in areas closest to the public during closures, and less time than expected by chance in these areas when the facility was open $\left(\chi^{2}=8.41, p=0.00373\right)$. Further analysis of closure compared when open $<1$ month and open $>1$ month revealed differences in enclosure use $\left(\chi^{2}=10.746, \mathrm{df}=4, p=0.03\right)$; zebra spent more time than would be expected by chance in areas closest to public viewing areas during closure periods $\left(\chi^{2}=8.41, p=0.00373\right)$. There were no significant differences between enclosure use during open $<1$ month and open $>1$ month observation periods.

\section{Discussion}

Previous research into the impacts of COVID-19 facility closures on zoo animal behaviour and enclosure usage has indicated variable behavioural responses [5]. Similar results are also reported in literature investigating HAIs in species during opening hours (e.g., sumatran orangutan (Pongo pygmaeus abelii) Bloomfield et al. [13]; kangaroos (Macropus fuliginosus fuliginosus) and red kangaroos (Macropus rufus) Sherwen et al. [14]; little penguins (Eudyptula minor) Chiew et al. [15]; western lowland gorillas (Gorilla gorilla gorilla) Lewis et al. [16]. Through this research we sought to expand on previous work [5] linked to zoo-closures to determine whether the variable behavioural responses to zoo closures during the COVID-19 pandemic were applicable across a wider subset of species. Furthermore, we sought to understand whether behavioural responses changed over time, enabling an understanding of the fundamental question: 'do zoo animals habituate to visitors?'.

Behavioural changes between facility closure and reopening periods were variable. For the majority of study species, no significant behavioural changes were observed between periods of zoo closure and re-opening or later in time (>1 month opening). However, Grevy's zebra performed significantly more comfort behaviour during closures than when the facility reopened, and the Chinese goral engaged in more environmental interaction when the zoo was closed; no environmental interaction was observed when the zoo was 
open. The low number of significant behavioural differences suggests that the sudden reduction of visitors from pre-COVID to no visitors (zoo closures) and the subsequent return of visitors did not lead to overt behavioral alteration in any species. Whilst significant differences were seen in frequency of comfort behaviour and environmental interaction, these behaviours were not 'replaced' by behaviours indicative of reduced welfare when facilities reopened, and no extreme responses to visitors (in terms of positive or negative human animal interactions or excessive vigilance) were recorded for either of these species, suggesting a lack of negative behavioural change due to visitor presence.

The animals' response to visitors was negligible during the observation periods. The majority of the species observed neither sought interactions with humans nor avoided humans. However, Chapman's zebra and Rothschild's giraffe only engaged in positive human-animal interactions (HAIs) during closure periods and Amur leopard only engaged in negative HAIs in the first month post reopening. The positive HAIs seen in Chapman's zebra and Rothschild's giraffe observed during closure periods could be the result of previous experiences as part of zoo routines. Individual animals experience environments in different ways [17] and their perception of zoo visitors may be affected by individual personalities and previous experiences [3]. Pre-COVID, Rothschild's giraffe at Zoo B were used in feeding encounters with zoo visitors [18] and the absence of zoo visitors may have led them to seek out interactions with keepers, or 'look for' the public, as was anecdotally reported in other species such as chimpanzees (Pan troglodytes) [19]. The increase in positive HAIs may also be a result of keepers spending longer trying to 'entertain' animals, keeping them stimulated and occupied during the zoo-closures by providing a range of novel enrichment [20] and spending longer with the animals [21]. Baker [22] showed that when keepers spent ten minutes longer with captive chimpanzees it increased the chimpanzee's positive behavioural responses, which could also explain this situation.

The avoidance of humans observed by the Amur leopard in the first month after opening was observed on the first day that the facility reopened to the public. Avoidance behaviours have been identified as indicators of fear in some species [3], and anecdotal reports from a Japanese aquarium highlighted that garden eels were 'hiding' from keepers [6]. The short-lived nature of the avoidance behaviour seen in the Amur leopard, in this study, is potentially indicative of visitors on the first day of reopening being an acute stressor for the species that may be linked to prolonged visitor absence. [18]. However, other behavioural indicators of increased fear (e.g., excessive vigilance, increased stereotypies) were not recorded. We propose that this may have been an initial reaction to the public returning, before re-habituation to visitors and their normal routine. Whilst Margulis et al. [23] found no effect of visitor numbers on Amur leopard activity levels, our findings highlight that they may take time to respond positively to changes in visitor presence building on repeated positive HAIs [24,25]. This is particularly pertinent whilst facilities are opening for short periods of time, and visitor numbers fluctuate at a low level. If visitors are perceived as a stressful stimulus by animals, which may arise if animals are not able to avoid visitors when they return or if visitors are not appropriately managed, they may become a repetitive acute stressor for animals [3] and there is the potential for the re-habituation period to increase.

Across a variety of species, research indicates animals are stimulated by the presence of visitors (spider monkey (Ateles geoffroyii rufiventris) [26]; parma wallaby (Macropus parma) [27]; various [28]) and in some instances they have been identified as a source of enrichment [13]. The removal of this stimulus i.e., when zoos are closed, may result in reduced activity. There is the potential for facility closures and the subsequent lack of zoo visitors to impact negatively on the physical health in zoo animals for example decreased activity leading to potential weight gain $[29,30]$ and potential foot health complications in some species, such as hoof overgrowth in giraffe [31]. We did not record significant reduced activity in species during this study and it was beyond the scope of this study to investigate physical and physiological parameters. However, as is highlighted above, throughout closure periods many facilities were documenting a range of 'novel' approaches 
to engage species in other ways in the absence of zoo visitors, so this may have negated the absence of stimulation provided by zoo visitors, and ensured species remained active throughout closures.

Wallabies were the only study species which were housed in a walk-through exhibit. Although not significant, wallabies engaged in increased vigilance behaviour over the periods of time from closed to open $>1$ month. Sherwen et al. [14] identified increased visitor vigilance in red kangaroos housed in a walk-through exhibit, when visitors increased. Although no corresponding increase was seen in general vigilance and decreased resting was observed, and there was no effect of visitor presence on proximity to visitor walkways [14]. Similar results were identified in our study as the swamp wallaby had relatively equal zone usage (indicated by SPI values) during both closure periods and open periods, and the proportion of time they spent near visitor pathways was no different to what would be expected by chance, regardless of observation period. In addition, a study looking at comparisons between walkthrough and more standard, non-walk through exhibits in Bennett's wallabies (Macropus rufogriseus) suggested greater levels of feeding behaviour in wallabies housed in the standard exhibits, despite no difference in enclosure utilisation [32]. Previous research into the impact of walk-through exhibits on animal welfare and the potential for unsupervised HAIs has indicated that there was no impact on vigilance towards visitors or distance from visitors with varying visitor numbers [33]. As animals in walk-through exhibits have the opportunity to engage in physically close interactions with the public, future research is needed to investigate the impact of enclosure use by wallabies with more varied visitor numbers. We advocate further research into the impact of facility closures on species housed in walk-through exhibits, to determine whether similar behavioural changes and enclosure use occur across other species, such as ring-tailed lemurs (Lemur catta) and free-ranging bird species.

It is important to note that post-closure visitor numbers were not representative of 'normal' zoo visitor frequencies and whilst these increased as government restrictions were updated (an allocation of at least 28.3-square-foot circle per person: [10]), they were still not as high as 'pre covid' numbers. However, animals may be more used to variations in visitor presence than we had first believed; their environments are variable. Prior to COVID-19 closures, zoo visitors had unrestricted access to public areas and random route planning within zoos, visitor presence could therefore be unpredictable and intense, and depending on how animals perceive this interaction could result in a positive or negative valence for species [3]. For example, visitor density and behaviour can impact on animal behaviour; Bornean orangutans (Pongo pygmaeus) increased head covering and increased vigilance when the density and noise of visitors increased, respectively [34].

The relative restriction of zoo environments post covid-19 may change the way that animals interact with zoo visitors. Overall, the number of visitors in the zoo at any one time was limited, visitors had to pre-book sessions and the entrance procedures were staggered to minimise large gatherings [18]. These processes and limitations may lead to more visitors than would usually be expected on some days (e.g., rainy days, when visitors may have been less willing to visit zoological facilities) or less than would usually be expected (e.g., sunny days). Generally speaking, this newer visitor management system may seemingly smooth the peaks and troughs of zoo visitor numbers. The limitation of restricted numbers of visitors at observation points (e.g., one family pod at a time) may also have led to visitors moving to other exhibits, rather than gathering in large groups at enclosure windows for long periods of time. Furthermore, the presence of zoo personnel near exhibits to help with management of the public (and the presence of zoo personnel during observations) may also have suppressed any more extreme public behaviours (e.g., calling out to animals to attract attention or banging on enclosure windows), which may have more negative effects on species [35]. 


\section{Study Limitations and Areas for Future Research}

The opportunistic nature of this work, undertaking research in a global pandemic led to a number of limitations. Whilst the results have been interpreted with these in mind, we believe it is prudent to highlight these clearly here. This research was designed to be simple, quick and easily repeatable across any facility to enable a higher uptake of participation whilst operating on minimal staff. Whilst this led to a loss of detailed data such as the frequency of behaviour at an individual level, it did enable a wide scale approach to gathering data which enabled collection of data on multiple species at multiple locations. Of note is the fact that when looking at enclosure usage we were not considering biological relevance of the zones, just basic proximity to the public, to enable comparisons across facilities. By investigating change within individual species, we were able to document in a simple manner the relationship between enclosure use and visitor presence, and determine whether study species were spending time nearer or further away from public viewing areas during closure and facility open periods, but we were not able to expand upon this in terms of understanding how enclosure usage was related to resource provision in the environment.

Furthermore, due to the opportunistic nature of data collection and the limited staffing at facilities, different staff were needed to undertake observations. Inter-rater reliability could not be undertaken due to staffing restrictions. There is thus the potential for some observer discrepancy, however we believe this to have minimal impact on the rigour of the data collection methods as all observers were very experienced with the species they were observing and also in undertaking behavioural observations, which are routinely undertaken across species as part of routine on-site welfare assessments [36].

The sample sizes of species and number of observation sessions per species in this research are relatively small. Thus, whilst this was representative of species held in the surveyed collections and is typical in zoo research [37,38], we highlight the need for these data to be treated as case studies, and they may not be readily generalised to the wider zoo population. Nevertheless, they serve to highlight a point that has already been raised by Williams et al. [5], that COVID-19 zoo closures and subsequent re-openings have had mixed effects on species. Whilst it was beyond the scope of this study to consider physical and physiological parameters of welfare, we would advocate including such measures in future work to provide a greater understanding of the impact of visitors and HAIs in zoo animals. Due to the small sample sizes, it is also important to tease apart biological relevance from significant differences. Small sample sizes may have led to a lack of statistically significant results but behaviours such as reduced vigilance over time (e.g., in the Amur leopards) are indicative of species re-habituating to the presence of zoo visitors over time. The repeated closures and reopenings may have negative effects on species that take longer to habituate to zoo visitors, and so further work which answers fundamental questions in relation to habituation of zoo animals to visitors over prolonged periods of time greater than 1 month, and as visitor numbers increase is strongly advocated.

Finally, these results represent snapshots of animal behaviour alone and thus cannot be interpreted as a complete representation of animal activity or stand-alone welfare measures. Data was gathered in a repeatable manner, over a long period of time in a wide range of species, which provides an opportunity to understand how a range of species in UK and Irish zoos have responded to facility closures. This leads to an enhanced understanding of the impact of covid-19 closures and visitor presence on animal behaviour. Prior to this, there has been no multi-species investigation into the impact of the covid-19 facility closures on animal behaviour specifically in zoos. We would recommend consideration of physiological measurements to further understand whether animals are displaying physiological changes, as well as behavioural changes, in response to facility reopenings and corresponding increases in visitors.

We advocate carrying out research such as this across facilities as zoos begin to reopen following the repeated and prolonged closures, to document whether the corresponding increases in visitors over time cause behavioural and physiological changes within species. 
The species reported in this study showed relatively few behavioural changes, however this may represent the relationships they typically had with visitors pre-closures. Previous research has indicated behavioural changes in some species which are frequently used as ambassador species, but not all [5]. The majority of the early HAI literature focused on the relationship between zoo visitors and primates, and much research since has suggested that many primate species attempt to engage with members of the public during facility opening hours $[39,40]$, and therefore primate-visitor relationships can be very complex. It could therefore be assumed that primates would be more likely to show significant impacts of facility closures, and subsequent reopenings, than species that do not traditionally engage with humans to such a great degree. Understanding human-animal interactions, in particular understanding how zoo animals habituate to visitors, and implications for zoo animals is imperative as part of evidence-based approaches to animal welfare, through the provision of appropriate environments in which animals can thrive [41].

\section{Conclusions}

As with previous research into the impacts of COVID-19 closures on animal behaviour and enclosure use, behavioural responses were variable across the study species. However, no overt negative behavioural responses were observed in the study animals post facility reopenings. Zoo animals, being captive bred, may be well adapted to the variable nature of their zoo environments and the natural flux in visitor numbers throughout the day and across the year. Whilst there is the potential for some species to take longer to re-habituate to the presence of zoo visitors, in the species studied, there was no behavioural evidence of a negative impact of zoo closures. As facility closures/reopenings are ongoing, we advocate a longitudinal monitoring approach which will enable evidence-based decisions to be made in regard to zoo visitor management during these periods. Furthermore, we recommend incorporation of physical and physiological measures of welfare where possible, alongside behavioural responses, to enable a holistic approach to answering fundamental questions on whether animals habituate to zoo visitors.

Author Contributions: Conceptualization, E.W., A.C., J.R. and S.J.W.; methodology, E.W., A.C., J.R. and S.J.W.; formal analysis, E.W.; writing-original draft preparation, E.W., A.C., J.R. and S.J.W.; writing-review and editing, E.W., A.C., J.R. and S.J.W.; project administration, E.W.; funding acquisition, E.W., A.C. and S.J.W. All authors have read and agreed to the published version of the manuscript.

Funding: Analysis and report writing has been supported by funding from Nottingham Trent University.

Institutional Review Board Statement: All research protocols were approved by Nottingham Trent University, School of Animal, Rural and Environmental Sciences School Ethics Group (reference number ARE192042) and meet the ARRIVE guidelines where necessary. Permission to conduct the study was granted by the participating zoos prior to commencement of data collection.

Informed Consent Statement: Not applicable.

Data Availability Statement: The data presented in this study are available on request from the corresponding author, subject to permission from study facilities.

Acknowledgments: Special thanks are extended to Edinburgh Zoo and Twycross Zoo to staff members who spent time collecting data under very difficult circumstances, this work would not have been possible without their support. Thanks, are also given to Eleanor Avery, Dayna Gordon, Paris Warren and Mary Wu for assistance with processing this data in a timely manner. Analysis and report writing has been supported by funding from Nottingham Trent University, for which the authors wish to extend their gratitude.

Conflicts of Interest: The authors declare no conflict of interest. 


\section{References}

1. Hosey, G.R. Zoo animals and their human audiences: What is the visitor effect? Anim. Welf. 2000, 9, 343-357.

2. Hosey, G. A preliminary model of human-animal relationships in the zoo. Appl. Anim. Behav. Sci. 2008, 109, 105-127. [CrossRef]

3. Sherwen, S.L.; Hemsworth, P.H. The visitor effect on zoo animals: Implications and opportunities for zoo animal welfare. Animals 2019, 9, 366. [CrossRef] [PubMed]

4. BIAZA. Zoos Desperate as $£ 95$ Million of Support Could 'Disappear'. Available online: https://biaza.org.uk/news/detail/zoosdesperate-as-95-million-of-support-could-disappear (accessed on 15 February 2021).

5. Williams, E.; Carter, A.; Rendle, J.; Ward, S.J. Understanding impacts of zoo visitors: Quantifying behavioural changes of two popular zoo species during Covid-19 closures. Appl. Anim. Behav. Sci. 2021, 236, 105253. [CrossRef]

6. McCurry, J. Japanese aquarium urges public to video-chat eels who are forgetting humans exist. The Guardian, 2020. Available online: https:/ / www.theguardian.com/world/2020/may/01/japanese-aquarium-urges-public-to-video-chat-eels-who-areforgetting-humans-exist (accessed on 8 March 2021).

7. BBC News. Coronavirus: Twycross Zoo's Apes 'Missing Human Interaction'. 2020. Available online: https://www.bbc.co.uk/ news/uk-england-leicestershire-52905647 (accessed on 8 March 2021).

8. Anderson, J. 'Looking for people': Zoo Animals Call out to Community during Coronavirus Closure. 2020. Available online: https:/ / www.sacbee.com/entertainment/article242079736.html (accessed on 8 March 2021).

9. Williams, E.; Rendle, J. How Captive Animals are Coping with the Sudden Emptiness of the World's Zoos and Aquariums. The Conversation, 2020. Available online: https://theconversation.com/how-captive-animals-are-coping-with-the-suddenemptiness-of-the-worlds-zoos-and-aquariums-138668 (accessed on 8 March 2021).

10. The Global Association for the Attractions Industry. Covid-19 Reopening Guidance: Considerations for the Global Attractions Industry. 2020. Available online: https://www.iaapa.org/sites/default/files/2020-05/IAAPA_COVID-19_ReopeningGuidance_ final.pdf (accessed on 15 February 2021).

11. Dickens, M. A statistical formula to quantify the "spread-of-participation" in group discussion. Speech Monogr. 1955, 22, 28-31. [CrossRef]

12. Plowman, A. A note on a modification of the spread of participation index allowing for unequal zones. Appl. Anim. Behav. Sci. 2003, 83, 331-336. [CrossRef]

13. Bloomfield, R.C.; Gillespie, G.R.; Kerswell, K.J.; Butler, K.L.; Hemsworth, P.H. Effect of partial covering of the visitor viewing area window on positioning and orientation of zoo orangutans: A preference test. Zoo Biol. 2015, 34, 223-229. [CrossRef] [PubMed]

14. Sherwen, S.L.; Hemsworth, P.H.; Butler, K.L.; Fanson, K.V.; Magrath, M.J.L. Impacts of visitor number on kangaroos housed in free-range exhibits. Zoo Biol. 2015, 34, 287-295. [CrossRef]

15. Chiew, S.J.; Butler, K.L.; Sherwen, S.L.; Coleman, G.J.; Melfi, V.; Burns, A.; Hemsworth, P.H. Effect of covering a visitor viewing area window on the behaviour of zoo-housed little penguins (Eudyptula minor). Animals 2020, 10, 1224. [CrossRef]

16. Lewis, R.N.; Chang, Y.M.; Ferguson, A.; Lee, T.; Clifforde, L.; Abeyesinghe, S.M. The effect of visitors on the behavior of zoo-housed western lowland gorillas (Gorilla gorilla gorilla). Zoo Biol. 2020, 39, 283-296. [CrossRef] [PubMed]

17. Špinka, M.; Wemelsfelder, F. Environmental challenge and animal agency. In Animal Welfare, 2nd ed.; Appleby, M., Mench, J., Olsson, I.A., Hughes, B., Eds.; Oxford Press: Oxford, UK, 2011; pp. 27-44.

18. Rendle, J. (Twycross Zoo, Atherstone, Warwickshire, UK). Personal Communication, 2021.

19. Mack, T. Animals at Twycross Zoo 'are missing visitors'. Leicestershire Live, 2020. Available online: https:/ / www.leicestermercury. co.uk/news/local-news/animals-twycross-zoo-are-missing-4119435 (accessed on 15 February 2021).

20. Funnel, R. This is how zoos across the world are keeping their animals stimulated during lockdown. IFLScience, 2020. Available online: https:/ / www.iflscience.com/plants-and-animals/this-is-how-zoos-across-the-world-are-keeping-their-animalsstimulated-during-lockdown/ (accessed on 15 February 2021).

21. Williams, S. Coronavirus: Animals in zoos 'lonely' without visitors. BBC News, 2020. Available online: https://www.bbc.co.uk/ news / world-52493750 (accessed on 15 February 2021).

22. Baker, K.C. Benefits of positive human interaction for socially-housed chimpanzees. Anim. Welf. 2004, 13, 239-245.

23. Margulis, S.W.; Hoyos, C.; Anderson, M. Effect of felid activity on zoo visitor interest. Zoo Biol. 2003, 22, 587-599. [CrossRef]

24. Hosey, G. Hediger revisited: How do zoo animals see us? Appl. Anim. Behav. Sci. 2013, 16, 338-359. [CrossRef]

25. Ward, S.J.; Melfi, V. Keeper-animal interactions: Differences between the behaviour of zoo animals affect stockmanship. PLoS ONE 2015, 10, e0140237. [CrossRef]

26. Davis, N.; Schaffner, C.M.; Smith, T.E. Evidence that zoo visitors influence HPA activity in spider monkeys (Ateles geoffroyii rufiventris). Appl. Anim. Behav. Sci. 2005, 90, 131-141. [CrossRef]

27. Rendle, J.; Ward, S.J.; McCormick, W.D. Behaviour and enclosure use of captive parma wallabies (Macropus parma): An assessment of compatibility within a mixed-species exhibit. J. Zoo Aquar. Res. 2018, 6, 63-68.

28. Queiroz, M.B.; Young, R.J. The different physical and behavioural characteristics of zoo mammals that influence their response to visitors. Animals 2018, 8, 139. [CrossRef] [PubMed]

29. Salas, M.; Manteca, X. Assessing welfare in zoo animals: Animal-based indicators. Zoo Anim. Welf. Educ. Centre 2016, 4, 2016.

30. Caravaggi, A.; Plowman, A.; Wright, D.J.; Bishop, C.M. The composition of captive ruffed lemur (Varecia spp.) diets in uk zoological collections, with reference to the problems of obesity and iron storage disease. J. Zoo Aquar. Res. 2018, 6, 41-49.

31. Dadone, L. Lameness diagnosis and management in zoo giraffe. Zoo Wild Anim. Med. 2018, 9, 623-629. 
32. Beaudin-Judd, J. The Impact of the Open and Closed Exhibit Designs on Captive Bennett's Wallaby (Macropus rufogriseus) Behaviour and Visitor Experience. Ph.D. Thesis, Concordia University, Montreal, QC, Canada, 2017.

33. Sherwen, S.L.; Magrath, M.J.; Butler, K.L.; Phillips, C.J.; Hemsworth, P.H. A multi-enclosure study investigating the behavioural response of meerkats to zoo visitors. Appl. Anim. Behav. Sci. 2014, 156, 70-77. [CrossRef]

34. Birke, L. Effects of browse, human visitors and noise on the behaviour of captive orang utans. Anim. Welf. 2002, 11, 189-202.

35. Blaney, E.; Wells, D. The influence of a camouflage net barrier on the behaviour, welfare and public perceptions of zoo-housed gorillas. Anim. Welf. 2004, 13, 111-118.

36. BIAZA. 2021 BIAZA Welfare Toolkit. Available online: https:/ /biaza.org.uk/projects/detail/biaza-welfare-toolkit-2 (accessed on 24 February 2021).

37. Bishop, J.; Hosey, G.; Plowman, A. Handbook of Zoo and Aquarium Research: Guidelines for Conducting Research in Zoos; BIAZA: London, UK, 2013.

38. Ward, S.J.; Hosey, G. The need for a convergence of agricultural/laboratory and zoo-based approaches to animal welfare. Appl. Anim. Behav. Sci. 2020, 23, 484-492. [CrossRef] [PubMed]

39. Collins, C.; Marples, N. The effects of zoo visitors on a group of western lowland gorillas (Gorilla gorilla gorilla) before and after the birth of an infant at dublin zoo. Int. Zoo Yearb. 2016, 50, 183-192. [CrossRef]

40. Hashmi, A.; Sullivan, M. The visitor effect in zoo-housed apes: The variable effect on behaviour of visitor number and noise. J. Zoo Aquar. Res. 2020, 8, 268-282.

41. Meehan, C.L.; Mench, J.A.; Carlstead, K.; Hogan, J.N. Determining connections between the daily lives of zoo elephants and their welfare: An epidemiological approach. PLoS ONE 2016, 11, e0158124. [CrossRef] 